\title{
Intraoperative Parathyroid Hormone Testing: Who Should Be the Target?
}

\author{
Dawn M. Elfenbein • David F. Schneider
}

Published online: 12 February 2014

(C) Springer Science + Business Media New York 2014

\begin{abstract}
Intraoperative parathyroid hormone (iPTH) monitoring has significantly altered the approach to surgical management of hyperparathyroidism, from the traditional four-gland exploration to minimally invasive parathyroidectomy. Several published criteria for iPTH predict operative cure with good accuracy, though iPTH should always be interpreted against the background of a surgeon's suspicion for multigland disease. Preoperative calcium and PTH levels as well a thorough understanding of the preoperative imaging modalities and their limitations is crucial. Current surgical strategies and iPTH utilization for four distinct patient populations are discussed.
\end{abstract}

Keywords Primary hyperparathyroidism $\cdot$ Secondary hyperparathyroidism $\cdot$ Tertiary hyperparathyroidism .

Parathyroid hormone $\cdot$ Intraoperative parathyroid monitoring · Minimally invasive parathyroidectomy · Intraoperative parathyroid hormone testing · Localized adenoma

\begin{abstract}
Abbreviations
PTH Parathyroid hormone

iPTH Intraoperative parathyroid hormone

MIP Minimally invasive parathyroidectomy

MGD Multigland disease
\end{abstract}

This article is part of the Topical Collection on Minimally Invasive Endocrine Surgery.

D. M. Elfenbein $(\bowtie) \cdot$ D. F. Schneider

Department of Surgery, General and Endocrine Surgery,

University of Wisconsin, 600 Highland Avenue, K4/739,

Madison, WI 53792-7375, USA

e-mail: elfenbein@surgery.wisc.edu

D. F. Schneider

e-mail: schneiderd@surgery.wisc.edu
MIBI Tc-99m sestamibi
US Ultrasound
PHPT Primary hyperparathyroidism
CT Computed tomography
MRI Magnetic resonance imaging

\section{Introduction}

Classically, the operative intervention for primary hyperparathyroidism (PHPT) was bilateral neck exploration with resection of one or more enlarged and hypersecreting parathyroid glands. This approach visualizes all four parathyroid glands and remains the recommended operation for secondary or tertiary hyperparathyroidism [1]. Parathyroid hormone (PTH) is an 84-amino acid peptide with a serum half-life of only 2-4 min [2]. In 1988, Dr. Nussbaum [3] described a decrease in PTH levels in the operating room during resection of a parathyroid adenoma and the concept of measuring PTH levels in real-time during an operation emerged. A drop in the PTH level could tell the surgeon when the hypersecreting gland or glands had been removed, thereby allowing for a more limited dissection. The first small series publishing use of intraoperative PTH (iPTH) levels to predict curative resection was published in 1991 [4]. This elegant technique rapidly gained favor, and faster assays were developed [57]. Combined with improvements in preoperative localization techniques, minimally invasive parathyroidectomy (MIP) has become preferred in many centers.

While the use of iPTH has been adopted widely and has transformed parathyroid surgery, the exact algorithm governing precisely how it should guide the conduct of the operation continues to be debated [8-13]. Several protocols 
Table 1 iPTH published protocols and criteria for operative cure

\begin{tabular}{|c|c|c|c|c|c|c|}
\hline & Sample 1 & Sample 2 & Sample 3 & Sample 4 & Sample 5 & Definition of surgical cure \\
\hline $\begin{array}{l}\text { Vienna criteria } \\
\text { [47] }\end{array}$ & $\begin{array}{c}\text { Pre-incision } \\
\text { (baseline) }\end{array}$ & $\begin{array}{l}10 \text { min post- } \\
\text { excision }\end{array}$ & $x$ & $x$ & & $\geq 50 \%$ drop from baseline at $10 \mathrm{~min}$ \\
\hline $\begin{array}{l}\text { Miami criteria } \\
\text { [46] }\end{array}$ & $\begin{array}{l}\text { Pre-incision } \\
\text { (baseline 1) }\end{array}$ & $\begin{array}{l}\text { Pre-excision } \\
\text { (baseline 2) }\end{array}$ & $\begin{array}{l}5 \text { min post- } \\
\text { excision }\end{array}$ & $\begin{array}{l}10 \text { min post- } \\
\text { excision }\end{array}$ & & $\begin{array}{l}\geq 50 \% \text { drop from higher baseline at } 10 \\
\text { min }\end{array}$ \\
\hline $\begin{array}{l}\text { Wisconsin } \\
\text { criteria [42] }\end{array}$ & Pre-incision & $\begin{array}{l}5 \text { min post- } \\
\text { excision }\end{array}$ & $\begin{array}{l}10 \text { min post- } \\
\text { excision }\end{array}$ & $\begin{array}{l}15 \text { min post- } \\
\text { excision }\end{array}$ & $\begin{array}{l}20 \text { min post- } \\
\text { excision }^{\mathrm{a}}\end{array}$ & $\begin{array}{l}\geq 50 \% \text { of baseline at any time point, if } \\
5 \text { min PTH is elevated above baseline, } \\
\text { that number becomes "new baseline" } \\
\text { and a } 20 \text { min sample is drawn }\end{array}$ \\
\hline $\begin{array}{l}\text { Halle criteria } \\
\text { [47] }\end{array}$ & $\begin{array}{l}15 \text { min post- } \\
\text { excision }\end{array}$ & & & & & $\mathrm{PTH} \leq 35 \mathrm{pg} / \mathrm{mL}$ \\
\hline $\begin{array}{l}\text { Rome criteria } \\
\text { [11] }\end{array}$ & $\begin{array}{l}\text { Pre-incision } \\
\text { (baseline 1) }\end{array}$ & $\begin{array}{l}\text { Pre-excision } \\
\quad \text { (baseline 2) }\end{array}$ & $\begin{array}{l}10 \text { min post } \\
\text { excision }\end{array}$ & $\begin{array}{l}20 \text { min post } \\
\text { excision }\end{array}$ & & $\begin{array}{l}\geq 50 \% \text { from higher baseline at } 10 \mathrm{~min} \\
\text { and/or falling into the normal range at } \\
20 \mathrm{~min} \text { and } / \mathrm{or} \text { a fall of }>7.5 \mathrm{pg} / \mathrm{mL} \\
\text { between } 10 \text { and } 20 \mathrm{~min}\end{array}$ \\
\hline $\begin{array}{l}\text { Charleston } \\
\text { criteria [48] }\end{array}$ & $\begin{array}{l}\text { Pre-incision } \\
\text { (baseline 1) }\end{array}$ & $\begin{array}{l}\text { Pre-excision } \\
\quad \text { (baseline 2) }\end{array}$ & $\begin{array}{l}10 \text { min post- } \\
\text { excision }\end{array}$ & $\begin{array}{l}20 \text { min post- } \\
\text { excision }\end{array}$ & & $\begin{array}{l}>50 \% \text { drop from higher baseline and } \\
\text { return to normal range OR }>65 \% \\
\text { PTH drop at } 10 \text { min. If criteria not } \\
\text { met, }>50 \% \text { PTH drop and return to } \\
\text { normal range range at } 20 \text { min sample }\end{array}$ \\
\hline
\end{tabular}

In all, if the criteria for surgical cure are not met, conversion to four-gland exploration is recommended

${ }^{a}$ Drawn only if 5-min sample is higher than baseline

${ }^{\mathrm{b}}$ Drawn only if 10-min criteria are not met

for measuring levels and criteria for surgical cure have been published and are in use today (Table 1). In general, a PTH level is drawn from a peripheral vein before the surgical incision and serves as the baseline level. After resection of the target lesion, PTH is drawn after some defined number of minutes, and criteria for surgical cure are met when a percentage drop (usually $50 \%$ ) occurs or an absolute PTH value is reached. Exploration continues until the criteria are met or the surgeon identifies all four glands. Some surgeons advocate iPTH monitoring in all parathyroidectomies, but others advocate a more selective application [14]. One strategy is to abandon iPTH monitoring when both a high-quality technetium-99m sestamibi scan (MIBI) and ultrasound (US) concordantly localize a single adenoma [15-17]. Others conclude that when MIBI alone localizes a single adenoma, iPTH does not add value [18]. Still others argue in favor of routine bilateral exploration $[19,20]$, and others have explored its use in secondary and tertiary hyperparathyroidism [21, 22].

In this review, we will discuss the use of iPTH monitoring in four different but commonly encountered patient situations. The first patient group includes those with PHPT and a well-localized adenoma based on preoperative imaging studies. The second group are patients with PHPT but negative or discordant localization studies. Perhaps the most important factor to consider when interpreting iPTH levels during an operation is the surgeon's preoperative suspicion of multigland disease (MGD), and recent research has identified parameters that help make this distinction. Third, we will discuss patients with PHPT and recurrent or persistent disease, and finally we will review the use of iPTH monitoring in patients with secondary or tertiary hyperparathyroidism. Our aim is to review the recent literature about the utility of $\mathrm{iPTH}$ and its effect on outcomes for these patient populations.

\section{Localized Adenoma}

The diagnosis of PHPT today is commonly made after a high calcium level is found on biochemical testing for another purpose. We are detecting patients at an earlier stage, often prior to development of symptoms, and serum calcium levels are only slightly elevated [23]. However, even with mild elevations of serum calcium and PTH, patients with PHPT have significantly increased risks of developing cardiovascular and cerebrovascular disease, renal dysfunction and fractures compared to age- and gender-matched controls [24]. Therefore, for even asymptomatic or mild disease, surgical excision is generally recommended (Table 2) $[25,26,27 \cdot]$. More than $80 \%$ of PHPT is caused by a single gland adenoma, and identification of the best imaging protocol to localize that single gland has been the focus of numerous investigations [28]. Because interpreting iPTH levels during MIP is dependent on the preoperative suspicion of MGD, we will review some of the most recent literature regarding adenoma localization first. 
Table 2 Consensus guidelines for parathyroidectomy in asymptomatic PHPT

\begin{tabular}{ll}
\hline Measurement & 2008 Guidelines \\
\hline Serum calcium & $>1.0 \mathrm{mg} / \mathrm{dL}$ above upper limit of normal \\
Creatinine clearance & $<60 \mathrm{~mL} / \mathrm{min}$ \\
$\begin{array}{l}\text { Bone mineral } \\
\text { density }\end{array}$ & T-score $<-2.5$ at any site or previous fracture \\
Age & $<50$ years \\
\hline
\end{tabular}

Some clinicians still recommend parathyroidectomy when 24-h urinary calcium excretion $>400 \mathrm{mg}$, but this was removed from the official 2008 guideline. (Data from Bilezikian et al. [25])

Introduced in 1989, the most widespread tool for parathyroid imaging is the nuclear medicine MIBI scan [29]. The radiolabeled nucleotide 99-Tc MIBI is taken up by both thyroid and parathyroid tissue; it is cleared from thyroid tissue with a half-life of $30 \mathrm{~min}$, but is usually retained by abnormal parathyroid glands, revealing the adenoma on delayed images [30]. Various techniques such as single-proton emission computed tomography (SPECT) [31] and injection of a second isotope can improve localization, but often the two-dimensional image provides the surgeon enough information to localize an abnormal gland. Reading of MIBI scans is variable depending on the experience of the reader, and interpretations are more accurate when performed by high-volume radiologists and experienced parathyroid surgeons [32].

Ultrasound, specifically when performed by the operating surgeon, has been reported to be more accurate than MIBI for preoperative localization. Untch et al. [33] found that surgeon-performed US accurately localized adenomas in $87 \%$ of patients, while MIBI accurately localized adenomas only $76 \%$ of the time. The authors concluded that MIBI added no additional information if the adenoma is well localized by US and that MIBI should be used only for those patients with negative or unclear US. Arora et al. [34] came to the same conclusion and noted that MIBI scans performed after successful US localization add cost and patient inconvenience with little added benefit. A comprehensive study by Siperstein et al. [35॰] reviewed their experience with 916 patients with PHPT who all underwent preoperative US and MIBI. The initial operative approach was targeted at the localized gland, but then every patient underwent bilateral exploration to identify additional parathyroid pathology. US identified a single abnormal gland in $80 \%$ of patients, while MIBI identified a single gland in $74 \%$ of patients. US is portable and inexpensive, and can easily be repeated on the day of surgery in the operating room as a confirmatory study. It should be noted that these studies were all done in high-volume centers with experienced operators performing the study and interpreting the images.
The use of computed tomography (CT) scans for diagnosis has exponentially increased for all areas of the body in the past 3 decades. Around 3 million CT scans were done in 1980 in the USA, but well over 70 million are currently performed each year [36]. With this massive increase in use, it is not surprising that it has emerged as a modality for localizing parathyroid adenomas. Some authors have even suggested that CT be used as an alternative to MIBI as a first-line imaging study. Madorin et al. [37] report that thin-cut dynamic parathyroid CT correctly identified the side of the adenoma in $87 \%$ of patients, while MIBI was correct in only $74 \%$ of patients. They note that CT took only $5 \mathrm{~min}$ to perform, compared to over $300 \mathrm{~min}$ for MIBI. Charges for each study were similar, though CT delivers a higher dose of radiation. Most surgeons reserve $\mathrm{CT}$ for reoperative situations, or sometimes if MIBI or US have failed to localize a gland, and it is not commonplace for it to be ordered as the initial imaging test.

Often, patients are referred to a medical endocrinologist where a diagnosis of PHTP is confirmed, and imaging studies are completed prior to surgical referral. This multidisciplinary model has advantages, but the importance of good communication between surgical and medical endocrinologists cannot be understated to avoid unnecessary and excessive studies [38, 39]. Some referring physicians may be reluctant to refer a patient with a negative MIBI scan to a surgeon, presuming the surgeon will not operate with a negative study; however, it is precisely these patients with PHPT and negative studies that benefit most from referral to an experienced parathyroid surgeon [40]. Figure 1 suggests an initial approach to a patient with PHPT, with MIBI and US being the initial imaging modalities. Regardless of the imaging modality used for localization, the surgeon must exercise caution because no study is $100 \%$ accurate in diagnosing a single adenoma as the cause of PHPT. Siperstein et al. [35•] report that even when the preoperative location suggested a single adenoma, the final diagnosis for those US-identified single gland patients was only correct $75 \%$ of the time and $70 \%$ of the time for MIBI patients. Even when MIBI and US were concordant, $16 \%$ of patients were found to have additional parathyroid pathology on further exploration. The surgeon must be aware that MGD is always a possibility, and unrecognized MGD is one major reason for operative failure. We recommend $\mathrm{PTH}$ monitoring even in cases where imaging is convincing for a single adenoma, as it can prompt the surgeon to perform further exploration if the PTH does not drop appropriately.

If an adenoma is suggested by imaging, most experienced parathyroid surgeons will recommend MIP with iPTH monitoring. If, at the time of surgery, the suspicious gland identified on imaging is clearly enlarged on visual inspection, it should be resected and the time recorded as 


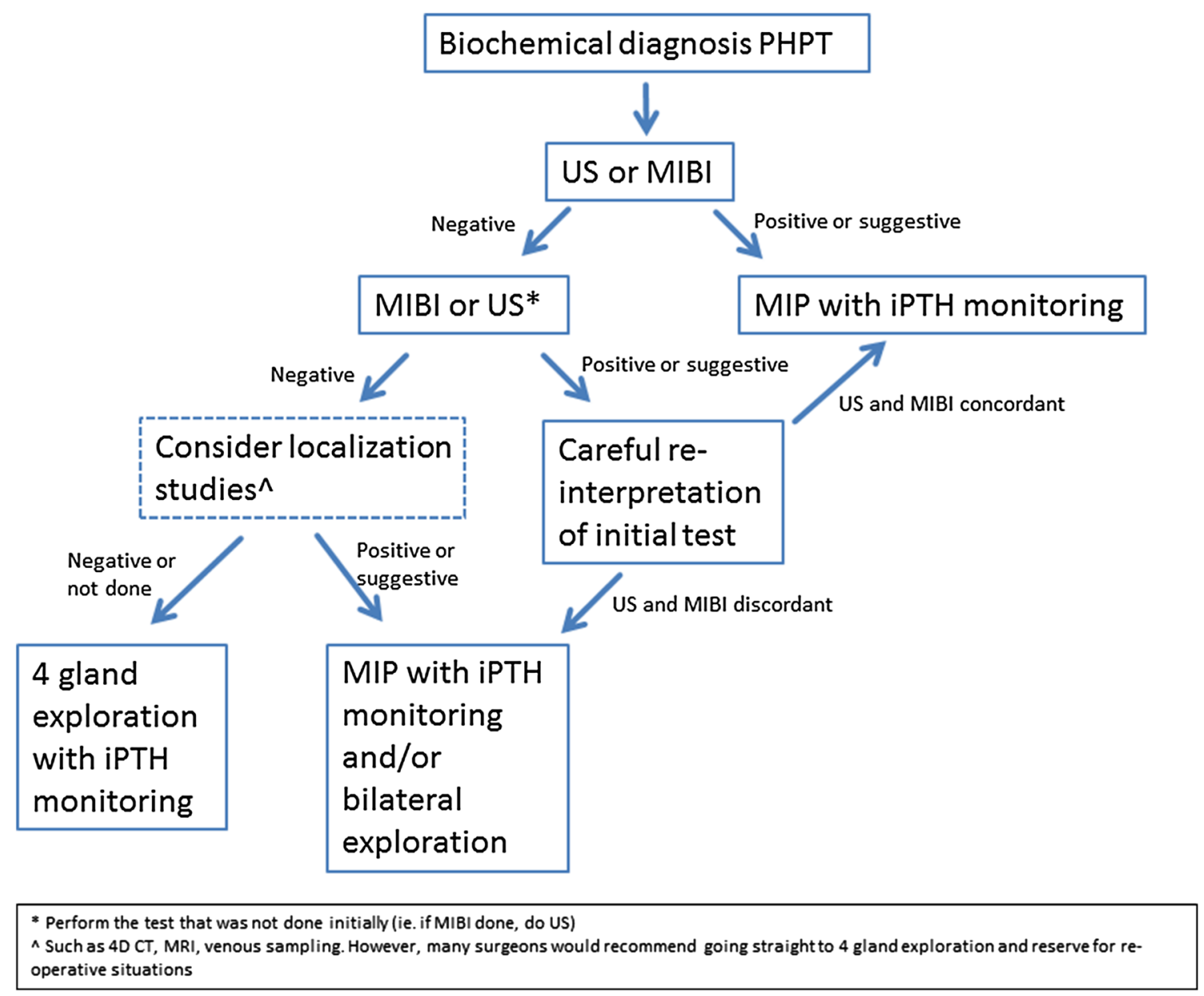

Fig. 1 Algorithm for the approach to a patient with PHPT

"time 0" for post-excision levels (Table 1). Occasionally, the first sample drawn is actually higher than the baseline because of manipulation of the gland and a surge of PTH into the bloodstream [41, 42]. Depending on the machine and assay used, it can take 15 min from the time the sample leaves the room to obtain the result, so a surgeon may choose to obtain hemostasis and close the incision before all samples are run. When using iPTH monitoring, the surgeon should not remove the drapes or break down the sterile table, however, until the criteria are met for surgical cure.

If iPTH levels do not fall appropriately, the incision should be re-opened, and a bilateral exploration with identification of all four glands should commence. Recent research has attempted to expand or elaborate criteria to avoid unnecessary explorations in the case of false-negative iPTH. O'Neal et al. [43] looked at 193 operations for localized parathyroid adenoma and found that in 48 of those operations, PTH levels did not fall after excision of the well-localized adenoma. In 16 of those patients (33\%), they determined that the inadequate drop in PTH levels was a false-negative result, in that patients were actually cured with no additional neck exploration. Kebebew et al. [44] developed the CaPTHUS scoring model for predicting single gland disease and found that high calcium levels ( $\geq 12 \mathrm{mg} / \mathrm{dL}$ ), high PTH levels ( $\geq 2 \times$ upper limit of normal), positive US or MIBI results for one gland, and concordant US/MIBI results all helped predict single gland disease. In fact, when three or more of these factors are present, MGD was $100 \%$ excluded in their study of 238 patients. Mazeh et al. [45 ${ }^{\circ}$ suggested a slightly more complicated nomogram that takes into account preoperative serum calcium and PTH levels (WIN category) along with the weight of the resected gland to predict the probability of remaining hypersecreting glands (Fig. 2). Both these studies suggest that in patients with lower preoperative serum calcium and PTH levels, a surgeon should have a heightened suspicion of MGD and a lower threshold for converting to bilateral exploration, particularly when the resected gland is small.

The published criteria in use today (Table 1) can be thought of in two broad categories. The first three criteria 
Fig. 2 Nomogram of the probability for another enlarged parathyroid gland in relation to the index gland by WIN categories. (Reprinted from Mazeh et al. [45•]; copyright 2013, Wolters Kluwer Health; with permission)

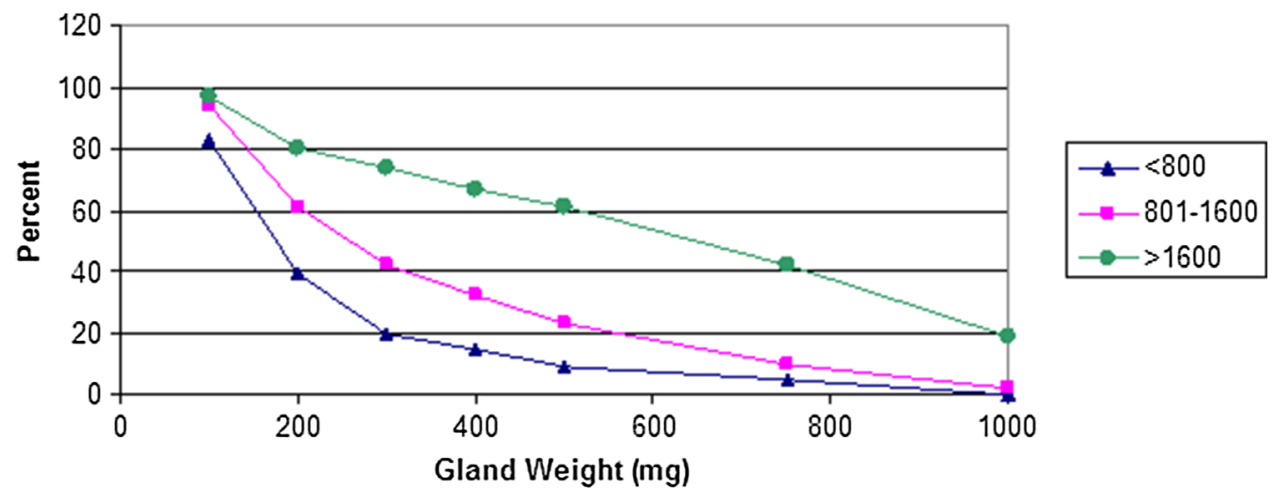

require a percentage drop in iPTH over time (Miami, Wisconsin, Vienna); the last three require a fall to some absolute concentration of PTH, usually somewhere in the normal range (Halle, Rome, Charleston). The Miami criteria or some variation on the Miami criteria is probably the most widely used [46]. The Vienna criteria [47] are identical except they do not require a pre-excision level and therefore do not take into account the potential for a rise in PTH from gland manipulation. The Wisconsin experience found that $50-60 \%$ of patients had levels drop by $50 \%$ at $5 \mathrm{~min}[27 \bullet]$, meaning the operation could be over 5 min earlier than when using the other two criteria. However, in $14 \%$ of patients, the 5-min sample was higher, so the criteria have an additional draw at $20 \mathrm{~min}$ in the situation where PTH increases at 5 min [42].

Of the criteria that require the iPTH level fall to some absolute value, the Rome criteria [11] are the most rigid, with criteria not only including a $50 \%$ drop, but also PTH needs to be in the normal range and dropping steadily over two time points (10 and $20 \mathrm{~min}$ ) for operative cure. The Halle criteria require no percentage drop, only that PTH should be in the low range of normal after $15 \mathrm{~min}$ [47]. Finally, the Charleston criteria require a $50 \%$ drop if that level is also in the normal range or at least a $65 \%$ drop for those patients with levels so elevated that a $50 \%$ drop would be above normal. They provide a second opportunity to meet criteria at $20 \mathrm{~min}$ if the criteria are not met at $10 \mathrm{~min}$ [48]. These criteria that require a fall into the normal range yield no false positives, but a much lower negative predictive value (26.3\% for Rome and $14.2 \%$ for Halle) because of the high number of false negatives. Using these criteria leads to more unnecessary bilateral explorations, but a surgeon can be essentially assured that a positive result means that there is no hyperfunctioning parathyroid tissue left behind. The criteria that require a $50 \%$ drop but no stipulation about the absolute value for PTH have a slightly lower positive predictive value (99.6\% for both Miami and Vienna), but a much improved negative predictive value of around $70 \%$ [10]. The experienced parathyroid surgeon needs to evaluate the trade- offs for each criterion and determine which is most appropriate to apply, understanding that none are perfect: each contributes some false negatives that lead a surgeon to perform an unnecessary bilateral exploration, but also some false positives that lead a surgeon to conclude an operation prematurely.

\section{Negative or Discordant Localization Studies}

In patients who have a diagnosis of PHPT and preoperative imaging fails to localize an enlarged gland, the decisionmaking algorithm becomes more challenging. As previously noted, practice patterns vary, and some surgeons prefer MIBI as the first localization study while others prefer US. Either way, if the first study fails to locate an enlarged gland, most surgeons will move on to a second study - a MIBI scan if the US was already done and vice versa - in an attempt to localize the disease preoperatively [40]. In the situations where one study localizes a gland but the other does not, or if the studies localize glands in different locations (superiorly or inferiorly in the same side of the neck or opposite sides of the neck), or if neither study localizes a gland, the surgeon should be aware of the potential need for bilateral exploration. Negative or discordant localization studies do not necessarily mean a patient has MGD, but the incidence is higher than for well-localized patients-up to $50 \%$ [35•]. Furthermore, the operative cure rate has been shown to be lower (93 vs. $97 \%$ ) for patients with negative or discordant studies [49]. It is in this group where some surgeons have recommend obtaining four-dimensional CT; Lubitz et al. [50] found that $4 \mathrm{D} \mathrm{CT}$ identified more than half of the abnormal glands missed by sestamibi and/or ultrasound, but it is unclear how much additional information 4D CT truly adds in this situation. Most experienced parathyroid surgeons would forego additional imaging with its associated costs and radiation risk and recommend performing a fourgland exploration.

When imaging is truly negative or discordant, the most conservative course of action is a four-gland exploration, 
but MIP may still be a possibility with iPTH guiding the extent of the operation. Amin et al. [51] sought to determine whether hyperfunctioning glands were more likely to be found in a particular location in cases of negative imaging, so as to recommend a starting point for MIP, but, unfortunately, found none. On re-review of images, a surgeon may notice subtle uptake or have some other reason (such as concomitant thyroid pathology) to start on one side or the other. In this situation, a unilateral exploration can be done. If an enlarged gland is found, the surgeon should identify the ipsilateral gland before proceeding. If the ipsilateral gland is normal, the enlarged gland should be removed and iPTH monitoring should proceed. If iPTH criteria for cure are met, the operation may be concluded, having explored only one side. Lew et al. [49] report that iPTH monitoring allowed for unilateral exploration in 56 of $85(66 \%)$ of patients with discordant imaging studies, avoiding bilateral exploration. However, if both glands on the same side appear either normal or abnormal, a surgeon should convert to a four-gland exploration and determine the appearance of the contralateral glands before deciding on the extent of resection.

Several intraoperative adjuncts are recommended when, after a thorough bilateral exploration, a surgeon is unable to locate an abnormal gland. Radio-guided parathyroidectomy involves injecting the patient with $10 \mathrm{mCi}$ of $99 \mathrm{mTc}$ sestamibi 1-2 $\mathrm{h}$ prior to surgery and using a hand-held gamma probe to scan the operative field for activity [52-54]. This technique can be helpful in experienced hands, but its routine use is yet to be recommended widely. Another technique that can be useful when exploration or imaging localization fails is differential internal jugular venous sampling. Prior to skin incision, the right and left internal jugular veins can be percutaneously accessed under ultrasound guidance as far low in the neck as is accessible [55, 56]. Alternatively, the veins may be directly accessed during an open operation where there are missing glands. The side with the hyperfunctioning gland should have a higher PTH concentration (at least 5-10\% higher), but it does not help guide the cranial/caudal position in the neck.

\section{Persistent or Recurrent Hyperparathyroidism}

Persistent hyperparathyroidism is defined by hypercalcemia that persists immediately after surgery or is diagnosed within 6 months; recurrent disease is hypercalcemia that normalizes after surgery, but re-develops after 6 months. Persistent disease is generally due to operative failurefailure to identify or remove all of the hyperfunctioning tissue-while recurrent disease often is due to regrowth of hyperfunctioning parathyroid. In either situation, the surgeon must be very thoughtful in preparation for a reoperation, as operating in a neck with scar tissue and previously violated tissue planes can be challenging and risky. All records pertaining to the initial diagnosis of PHPT should be reviewed, including the old localization studies, operative report, and pathology of the removed tissue. A diagnosis of a familial syndrome should be explored, and biochemical testing, including vitamin D levels and 24-h urine calcium, should be repeated to confirm the diagnosis.

Once the decision has been made to reoperate on persistent or recurrent disease, most surgeons endorse a more aggressive use of localization studies. Most experienced parathyroid surgeons would recommend starting over with US and MIBI, then moving on to 4D CT or MRI from the base of the skull to the diaphragm, looking for ectopic glands. Suspicious tissue can be accessed with fine-needle aspiration (FNA) using US guidance, and the aspirate can be sent for PTH assay [57]. Highly selective venous catheterization can be performed in those cases where imaging fails to localize a gland and is limited in the information that it provides in that it can help to lateralize a gland to one side or the other. Because venous drainage of parathyroids is variable and can be altered in a reoperative neck, and because of the invasiveness of this test, it should generally be employed only when all other localization efforts fail.

Despite the anxiety surrounding a reoperative parathyroid surgery, with good preoperative planning, most patients can be cured. Monitoring of iPTH can guide the operation in the same fashion as in first time surgeries and accurately predict removal of hyperfunctioning parathyroid tissue. Yen et al. [58] reported cure rates of $92 \%$ in reoperative parathyroidectomy using iPTH monitoring and a minimally invasive approach in $60 \%$ of patients. Richards et al. [59] reported a cure rate of $89 \%$ in reoperative parathyroidectomy and found that the use iPTH monitoring was predictive of cure and, interestingly, protective against permanent hypoparathyroidism. Hypoparathyroidism occurs when too much parathyroid tissue is removed, and iPTH monitoring may alert the clinician that too much tissue was removed, thus prompting the surgeon to perform autotransplantation of parathyroid tissue. In the study by Richards et al., however, autotransplantation rates did not differ in the iPTH group; the authors concluded that iPTH monitoring may have guided the surgeon toward a more focused and less invasive operation, with prevention of unnecessary and potentially damaging dissection.

\section{Secondary or Tertiary Hyperparathyroidism}

In hemodialysis patients, hyperphosphatemia and impaired conversion of 25-hydroxycholecalciferal to 1,25- 
dihydroxycholecalciferol in the kidney result in hypocalcemia. Hypocalcemia and hyperphosphatemia are both potent stimuli for PTH secretion; as a result, hyperplasia of the parathyroid glands occurs. This hyperparathyroidism is quite different from PHTP, as it is an exaggeration of the body's normal response to hypocalcemia, not an abnormally functioning gland. Because peripheral resistance to PTH also occurs in these patients and calcium remains persistently low, PTH levels can be extremely elevated, causing high bone turnover, osteoporosis, and, in extreme cases, calciphylaxis. Most secondary hyperparathyroidism is treated medically with vitamin D and calcium supplements, calcimimetics, and phosphate binders, but occasionally patients will be referred for parathyroidectomy. Tertiary hyperparathyroidism occurs when hyperparathyroidism persists after renal transplantation - instead of regressing, the parathyroid chief cells function autonomously after correcting the electrolyte imbalances that caused hyperparathyroidism. Tertiary hyperparathyroidism should always be treated with surgery.

Unlike PHPT, however, surgical cure for both secondary and tertiary hyperparathyroidism cannot be accomplished with a minimally invasive approach. These diseases are caused by hyperplasia of all four glands (although it can be asymmetric hyperplasia), and surgical cure always requires bilateral exploration to perform a subtotal or near total thyroidectomy, leaving behind either a small remnant of a single gland or removing all parathyroid tissue and autotransplanting a small amount of tissue into muscle. Some have argued, then, that iPTH monitoring is not useful in these diseases, as its primary use in PHPT is to guide the extent of the operation.

For surgeons who do use iPTH monitoring in secondary and tertiary disease, one must be cognizant of the fact that baseline PTH levels are several-fold higher than in primary disease, and decreased renal function leads to delayed PTH clearance. Therefore, several alternate criteria have been proposed. Pitt et al. [1] reported that for secondary hyperparathyroid patients, a $50 \%$ decrease from baseline is predictive of cure, but it does not alter the operation. In tertiary disease, however, iPTH can alter surgical management, as there is often a dominant gland found at the time of exploration. The authors found that when iPTH criteria are met after resection of a dominant gland in patients with tertiary disease, the more normal-appearing glands could be left in situ, sparing the patient the potential morbidity of a more extensive resection, while still allowing for long-term cure. Gasparri et al. [60] found iPTH to be a useful adjunct to MIBI and parathyroid weight in these patients by helping the surgeon to know that no ectopic tissue is present (i.e., if after removing four glands, iPTH remains elevated, the surgeon should search for an additional gland). Kim et al. [21] recommend an
$85 \%$ decline from baseline at 40 min post-subtotal thyroidectomy for the best prediction of cure, while Sharma et al. [61] advocate a near-total parathyroidectomy, leaving a vascularized remnant of one gland that approximates the size of two normal parathyroid glands and aims for an absolute final iPTH level of $100 \mathrm{pg} / \mathrm{mL}$.

\section{Potential Problems and Pitfalls}

Many surgeons prefer that iPTH monitoring be performed using peripheral access, while many anesthesiologists would prefer that the surgeon collect blood from the exposed jugular veins. Jugular venous sampling can be susceptible to errors in interpretation because these veins have higher concentrations of PTH, concentrations vary according to whether the sample is drawn proximal or distal to the hypersecreting gland, and PTH from the jugular system requires a longer time to fall into the normal range [62]. Peripheral sampling can be challenging because most surgeons will tuck the patients' arms during initial positioning, which makes intravenous catheters difficult to access and susceptible to kinking or bending. Intravenous catheters can be placed in a patient's foot to avoid these problems or arterial lines placed as they may be less vulnerable to positioning problems. If peripheral access is lost during the course of drawing timed samples, it is not a good idea to draw blood from the jugular and use that sample in the criteria for cure since concentrations can vary. The person drawing the sample must be careful to clear the line of fluid so as not to dilute the sample, and it should be promptly labeled with the time of the draw and sent immediately for analysis. Hemolysis of a sample can lower PTH concentrations: a hemolyzed pre-incision PTH can lead to false negatives, while hemolysis post-excision can result in false positives [63].

Rebounding PTH levels after meeting iPTH criteria for cure should always alert the surgeon to the possibility of MGD. Unfortunately, these levels sometimes are not known until the conclusion of the operation. For example, if a patient has a baseline PTH of $100 \mathrm{pg} / \mathrm{mL}$, and it drops to $50 \mathrm{pg} / \mathrm{mL}$ after resection of a single enlarged gland, the patient has met the criteria for cure, and the operation is concluded (Table 1). The next levels may have been drawn and are being run while the drapes are taken down and the patient is woken up. It may be when the patient is in the recovery room when the pattern emerges that the next PTH is barely lower than the post-excision level at $45 \mathrm{pg} / \mathrm{mL}$, and the final level rebounds to $65 \mathrm{pg} / \mathrm{mL}$. Re-exploration is difficult once the patient is in the recovery room, but if the rebound is profound, consideration should be given to returning to the operating room for an immediate reexploration. A thorough preoperative discussion with the 
patient and family about the limitations of iPTH can make this difficult discussion slightly easier. At the very least, most surgeons would recommend monitoring these patients more closely for recurrence [64•].

\section{Conclusions}

iPTH monitoring is a useful adjunct to preoperative localization studies in all patients with hyperparathyroidism; in PHPT and tertiary disease, it may alter the course of the operation, while in secondary disease, it is still useful in predicting postoperative cure. In every situation, cure rates are better in the hands of experienced parathyroid surgeons. Several criteria exist to predict operative cure, and criteria should be selected based on the particular patient situation and surgeon experience.

\section{Compliance with Ethics Guidelines}

Conflict of Interest Dawn M. Elfenbein and David F. Schneider declare that they have no conflict of interest.

Human and Animal Rights and Informed Consent This article does not contain any studies with human or animal subjects performed by any of the authors.

\section{References}

Papers of particular interest, published recently, have been highlighted as:

- Of importance

1. Pitt SC, Panneerselvan R, Chen H, et al. Secondary and tertiary hyperparathyroidism: the utility of ioPTH monitoring. World $\mathrm{J}$ Surg. 2010;34(6):1343-9.

2. Holt EH, Inzucchi SE. Physiology and pathophysiology of the parathyroid glands and preoperative evaluation. In: Oertli D, Udelsman R, editors. Surgery of the thyroid and parathyroid glands. New York: Springer; 2007. p. 236.

3. Nussbaum SR, Thompson AR, Hutcheson KA, et al. Intraoperative measurement of parathyroid hormone in the surgical management of hyperparathyroidism. Surgery. 1988;104(6):1121-7.

4. Irvin GL 3rd, Dembrow VD, Prudhomme DL. Operative monitoring of parathyroid gland hyperfunction. Am J Surg. 1991;162(4):299-302.

5. Rodgers SE, Lew JI. The parathyroid hormone assay. Endocrine practice: official journal of the American College of Endocrinology and the American Association of Clinical Endocrinologists. 2011;17(Suppl 1):2-6.

6. Terris DJ, Weinberger PM, Farrag T, et al. Restoring point-ofcare testing during parathyroidectomy with a newer parathyroid hormone assay. Otolaryngol Head Neck Surg. 2011; 145(4):557-60.

7. Jarrige V, Nieuwenhuis JH, van Son JP, et al. A fast intraoperative PTH point-of-care assay on the Philips handheld magnotech system. Langenbecks Arch Surg. 2011;396(3):337-43.
8. Seybt MW, Loftus KA, Mulloy AL, et al. Optimal use of intraoperative PTH levels in parathyroidectomy. Laryngoscope. 2009;119(7):1331-3.

9. Lupoli GA, Fonderico F, Panico A, et al. Stricter criteria increase the validity of a quick intraoperative parathyroid hormone assay in primary hyperparathyroidism. Med Sci Monit. 2009;15(3):Cr111-6.

10. Barczynski M, Konturek A, Hubalewska-Dydejczyk A, et al. Evaluation of Halle, Miami, Rome, and Vienna intraoperative iPTH assay criteria in guiding minimally invasive parathyroidectomy. Langenbecks Arch Surg. 2009;394(5):843-9.

11. Lombardi CP, Raffaelli M, Traini E, et al. Intraoperative PTH monitoring during parathyroidectomy: the need for stricter criteria to detect multiglandular disease. Langenbecks Arch Surg. 2008;393(5):639-45.

12. Gupta A, Unawane A, Subhas G, et al. Parathyroidectomies using intraoperative parathormone monitoring: when should we stop measuring intraoperative parathormone levels? Am Surg. 2012;78(8):844-50.

13. Richards ML, Thompson GB, Farley DR, et al. An optimal algorithm for intraoperative parathyroid hormone monitoring. Arch Surg. 2011;146(3):280-5.

14. Hwang RS, Morris LF, Ro K, et al. A selective, Bayesian approach to intraoperative PTH monitoring. Ann Surg. 2010;251(6):1122-6.

15. Bachar G, Mizrachi A, Hadar T, et al. Role of parathyroid hormone monitoring during parathyroidectomy. Head Neck. 2011;33(12):1754-7.

16. Sakimura C, Minami S, Hayashida N, et al. Can the use of intraoperative intact parathyroid hormone monitoring be abandoned in patients with hyperparathyroidism? Am J Surg. 2013;206(4):574-7.

17. Smith N, Magnuson JS, Vidrine DM, et al. Minimally invasive parathyroidectomy: use of intraoperative parathyroid hormone assays after 2 preoperative localization studies. Arch Otolaryngol Head Neck Surg. 2009;135(11):1108-11.

18. Opoku-Boateng A, Bolton JS, Corsetti R, et al. Use of a sestamibi-only approach to routine minimally invasive parathyroidectomy. Am Surg. 2013;79(8):797-801.

19. Suliburk JW, Sywak MS, Sidhu SB, et al. 1000 minimally invasive parathyroidectomies without intra-operative parathyroid hormone measurement: lessons learned. ANZ J Surg. 2011; 81(5):362-5.

20. Norman J, Lopez J, Politz D. Abandoning unilateral parathyroidectomy: why we reversed our position after 15,000 parathyroid operations. J Am Coll Surg. 2012;214(3):260-9.

21. Kim WY, Lee JB, Kim HY. Efficacy of intraoperative parathyroid hormone monitoring to predict success of parathyroidectomy for secondary hyperparathyroidism. J Korean Surg Soc. 2012; 83(1):1-6.

22. Roshan A, Kamath B, Roberts S, et al. Intra-operative parathyroid hormone monitoring in secondary hyperparathyroidism: is it useful? Clin Otolaryngol. 2006;31(3):198-203.

23. Almquist M, Bergenfelz A, Mårtensson $\mathrm{H}$, et al. Changing biochemical presentation of primary hyperparathyroidism. Langenbecks Arch Surg. 2010;395(7):925-8.

24. Yu N, Donnan PT, Flynn RW, et al. Increased mortality and morbidity in mild primary hyperparathyroid patients. The Parathyroid Epidemiology and Audit Research Study (PEARS). Clin Endocrinol. 2010;73(1):30-4.

25. Bilezikian JP, Khan AA, Potts JT Jr. Guidelines for the management of asymptomatic primary hyperparathyroidism: summary statement from the third international workshop. J Clin Endocrinol Metab. 2009;94(2):335-9.

26. Adler JT, Sippel RS, Schaefer S, et al. Surgery improves quality of life in patients with "mild" hyperparathyroidism. Am J Surg. 2009;197(3):284-90. 
27. - Schneider DF, Burke JF, Ojomo KA, et al. Multigland disease and slower decline in intraoperative PTH characterize mild primary hyperparathyroidism. Ann Surg Oncol. 2013;20(13): 4205-11. Highlights different characteristics of iPTH monitoring in mild hyperparathyroidism.

28. Mohebati A, Shaha AR. Imaging techniques in parathyroid surgery for primary hyperparathyroidism. Am J Otolaryngol. 2012;33(4): 457-68.

29. Coakley AJ, Kettle AG, Wells CP, et al. 99Tcm sestamibi-a new agent for parathyroid imaging. Nucl Med Commun. 1989;10(11): $791-4$.

30. Smith JR, Oates ME. Radionuclide imaging of the parathyroid glands: patterns, pearls, and pitfalls. Radiographics. 2004;24(4):1101-15.

31. Dasgupta DJ, Navalkissoor S, Ganatra R, et al. The role of singlephoton emission computed tomography/computed tomography in localizing parathyroid adenoma. Nucl Med Commun. 2013;34(7): 621-6.

32. Zia S, Sippel RS, Chen H. Sestamibi imaging for primary hyperparathyroidism: the impact of surgeon interpretation and radiologist volume. Ann Surg Oncol. 2012;19(12):3827-31.

33. Untch BR, Adam MA, Scheri RP, et al. Surgeon-performed ultrasound is superior to $99 \mathrm{Tc}$-sestamibi scanning to localize parathyroid adenomas in patients with primary hyperparathyroidism: results in 516 patients over 10 years. J Am Coll Surg. 2011;212(4):522-9.

34. Arora S, Balash PR, Yoo J, et al. Benefits of surgeon-performed ultrasound for primary hyperparathyroidism. Langenbecks Arch Surg. 2009;394(5):861-7.

35. - Siperstein A, Berber E, Barbosa GF, et al. Predicting the success of limited exploration for primary hyperparathyroidism using ultrasound, sestamibi, and intraoperative parathyroid hormone: analysis of 1158 cases. Ann Surg. 2008;248(3):420-8. Single institution, large-scale study of patients who underwent initial MIP followed by bilateral exploration.

36. Brenner DJ, Hall EJ. Computed tomography-an increasing source of radiation exposure. N Engl J Med. 2007;357(22): 2277-84.

37. Madorin CA, Owen R, Coakley B, et al. Comparison of radiation exposure and cost between dynamic computed tomography and sestamibi scintigraphy for preoperative localization of parathyroid lesions. JAMA Surg. 2013;148(6):500-3.

38. Kunstman JW, Kirsch JD, Mahajan A, et al. Clinical review: parathyroid localization and implications for clinical management. J Clin Endocrinol Metab. 2013;98(3):902-12.

39. Cheung K, Wang TS, Farrokhyar F, et al. A meta-analysis of preoperative localization techniques for patients with primary hyperparathyroidism. Ann Surg Oncol. 2012;19(2):577-83.

40. Elaraj DM, Sippel RS, Lindsay S, et al. Are additional localization studies and referral indicated for patients with primary hyperparathyroidism who have negative sestamibi scan results? Arch Surg. 2010;145(6):578-81.

41. Riss P, Asari R, Scheuba C, et al. PTH secretion of "manipulated" parathyroid adenomas. Langenbecks Arch Surg. 2009;394(5):891-5.

42. Cook MR, Pitt SC, Schaefer S, et al. A rising ioPTH level immediately after parathyroid resection: are additional hyperfunctioning glands always present? An application of the Wisconsin criteria. Ann Surg. 2010;251(6):1127-30.

43. O'Neal PB, Poylin V, Mowschenson P, et al. When initial postexcision PTH level does not fall appropriately during parathyroidectomy: what to do next? World J Surg. 2009;33(8): 1665-73.

44. Kebebew E, Hwang J, Reiff E, et al. Predictors of single-gland vs. multigland parathyroid disease in primary hyperparathyroidism: a simple and accurate scoring model. Arch Surg. 2006;141(8):
777-82.

45. - Mazeh H, Chen H, Leverson G, et al. Creation of a "Wisconsin index" nomogram to predict the likelihood of additional hyperfunctioning parathyroid glands during parathyroidectomy. Ann Surg. 2013;257(1):138-41. Model for predicting unsuspected MGD during parathyroidectomy.

46. Carneiro DM, Solorzano CC, Nader MC, et al. Comparison of intraoperative iPTH assay (QPTH) criteria in guiding parathyroidectomy: which criterion is the most accurate? Surgery. 2003;134(6):973-9 discussion 79-81.

47. Riss P, Kaczirek K, Heinz G, et al. A "defined baseline" in PTH monitoring increases surgical success in patients with multiple gland disease. Surgery. 2007;142(3):398-404.

48. Carneiro-Pla D. Contemporary and practical uses of intraoperative parathyroid hormone monitoring. Endocr Pract. 2011;17(Suppl 1):44-53.

49. Lew JI, Solorzano CC, Montano RE, et al. Role of intraoperative parathormone monitoring during parathyroidectomy in patients with discordant localization studies. Surgery. 2008;144(2): 299-306.

50. Lubitz CC, Hunter GJ, Hamberg LM, et al. Accuracy of 4-dimensional computed tomography in poorly localized patients with primary hyperparathyroidism. Surgery. 2010;148(6):1129-37.

51. Amin AL, Wang TS, Wade TJ, et al. Nonlocalizing imaging studies for hyperparathyroidism: where to explore first? J Am Coll Surg. 2011;213(6):793-9.

52. Cayo A, Chen H. Radioguided reoperative parathyroidectomy for persistent primary hyperparathyroidism. Clin Nucl Med. 2008; 33(10):668-70.

53. Chen H, Mack E, Starling JR. A comprehensive evaluation of perioperative adjuncts during minimally invasive parathyroidectomy: which is most reliable? Ann Surg. 2005;242(3):375-80.

54. Chen H, Mack E, Starling JR. Radioguided parathyroidectomy is equally effective for both adenomatous and hyperplastic glands. Ann Surg. 2003;238(3):332-7 discussion 37-38.

55. Barczynski M, Konturek A, Hubalewska-Dydejczyk A, et al. Utility of intraoperative bilateral internal jugular venous sampling with rapid parathyroid hormone testing in guiding patients with a negative sestamibi scan for minimally invasive parathyroidectomy-a randomized controlled trial. Langenbecks Arch Surg. 2009;394(5):827-35.

56. Ito F, Sippel R, Lederman J, et al. The utility of intraoperative bilateral internal jugular venous sampling with rapid parathyroid hormone testing. Ann Surg. 2007;245(6):959-63.

57. Prescott JD, Udelsman R. Remedial operation for primary hyperparathyroidism. World J Surg. 2009;33(11):2324-34.

58. Yen TW, Wang TS, Doffek KM, et al. Reoperative parathyroidectomy: an algorithm for imaging and monitoring of intraoperative parathyroid hormone levels that results in a successful focused approach. Surgery. 2008;144(4):611-9.

59. Richards ML, Thompson GB, Farley DR, et al. Reoperative parathyroidectomy in 228 patients during the era of minimalaccess surgery and intraoperative parathyroid hormone monitoring. Am J Surg. 2008;196(6):937-42.

60. Gasparri G, Camandona M, Bertoldo U, et al. The usefulness of preoperative dual-phase $99 \mathrm{mTc}$ MIBI-scintigraphy and IO-PTH assay in the treatment of secondary and tertiary hyperparathyroidism. Ann Surg. 2009;250(6):868-71.

61. Sharma J, Raggi P, Kutner N, et al. Improved long-term survival of dialysis patients after near-total parathyroidectomy. J Am Coll Surg. 2012;214(4):400-7.

62. Beyer TD, Chen E, Ata A, et al. A prospective evaluation of the effect of sample collection site on intraoperative parathormone monitoring during parathyroidectomy. Surgery. 2008;144(4):504-9. 
63. Moalem J, Ruan DT, Farkas RL, et al. Prospective evaluation of the rate and impact of hemolysis on intraoperative parathyroid hormone (IOPTH) assay results. Ann Surg Oncol. 2010;17(11): 2963-9.
64. - Schneider DF, Ojomo KA, Mazeh H, et al. Significance of rebounding parathyroid hormone levels during parathyroidectomy. J Surg Res. 2013;184(1):265-8. Rebounding iPTH levels signify high risk for MGD. 